\title{
FACTOR ANALYSIS OF INFLUENCE OF PARAMETERS OF WATER REGIME AND HYDROLOGICAL CHANGES ON PASTURES
}

\author{
Mazurkin P.M. \\ Doctor of Engineering, professor, Academician of Russian Academy of Natural History и Russian \\ Academy of Natural Sciences, member of the European Academy of Natural sciences, \\ Volga State University of Technology, Yoshkar-Ola, E-mail: kaf_po@mail.ru
}

\begin{abstract}
According to basic tabular data (DEFRA-commissioned project BD1310. Final report to the Department for Environment, Food and Rural Affairs) steady regularities between biochemical substances of the soil of pastures and hydrological parameters of their water mode are revealed. Shows the ranking methodology affecting and dependent factors and identification of deterministic models of the relationship between the 10 factors according to the general equation consisting of the sum of two biotechnical laws.
\end{abstract}

Keywords: pastures, options, rating, mutual influence, factor, analysis, patterns

1. Introduction. Analysis of binary relations between the 10 factors conducted on the data [1, p.44-45] (Appendix C. Soil parameters used in the hydrological modelling). Statistical modeling was performed by identification of General algebraic formula containing the sum of two biotechnical laws [2-5].

Factor analysis is understood as the identification of stable patterns of changes of values of each of the plurality of parameters of the studied systems, as well as mathematical relations between the factors. In comparison with the approximation in the methodology of identifying the truth of stable laws is accepted as an axiom. So there is no need of using empirical formula it is set in advance.

Our method of factor analysis allows not only to establish a posteriori causality, but also to give them a quantitative characteristic, provides an assessment of the level of influence of factors (influence parameters) on the results of functioning (dependent parameters). This makes factor analysis accurate method, and conclusions quantitatively valid and meaningful in the identification of regularities.

2. The source data. Us, it is assumed that the factors the researcher selected and the corresponding tabular model (tab. 1) was compiled. Then factor analysis is the identification of the algebraic relationships between the selected factors.

This will show a specific example [1]. From table 1 it is clear that they received some kind of grouping. Most often the grouping is performed by calculating the arithmetic mean value. If at our disposal were the primary measurement data, it would be possible to identify a more accurate statistical model on 10 indicators with consideration of the wave components. On average factors, there is a coarsening of the desired biotechnical regularities. Therefore, the wave functions do not identify, and the only deterministic model binary relations between factors. Rank relationship is not detected, for a one-dimensional relationship, the correlation coefficient is equal to 1 . 
Table 1. Soil parameters used in the hydrological modeling

\begin{tabular}{|l|c|c|c|c|c|}
\hline \multicolumn{1}{|c|}{ Site Name } & $\begin{array}{c}\text { Topsoil } \\
\text { hydraulic } \\
\text { conductivity } \\
\text { (m day) }\end{array}$ & $\begin{array}{c}\text { Subsoil } \\
\text { hydraulic } \\
\text { conductivity } \\
\text { (m day) }\end{array}$ & $\begin{array}{c}\text { Topsoil } \\
\text { drainable } \\
\text { porosity }\end{array}$ & $\begin{array}{c}\text { Subsoil } \\
\text { drainable } \\
\text { pororsity }\end{array}$ & $\begin{array}{c}\text { Unsaturated } \\
\text { Hydraulic } \\
\text { conductivity } \\
\text { exponent }\end{array}$ \\
\cline { 2 - 6 } & $x_{1}$ & $x_{2}$ & $x_{3}$ & $x_{4}$ & $x_{5}$ \\
\hline 1. Belaugh & 3.0 & 3.0 & 0.3 & 0.3 & 8 \\
\hline 2. Blackthorn & 0.22 & 0.01 & 0.06 & 0.03 & 3 \\
\hline 3. Broaddale & 0.7 & 0.35 & 0.14 & 0.09 & 4 \\
\hline 4. Cricklade & 0.24 & 3.5 & 0.12 & 0.12 & 7 \\
\hline 5. Dancing Gate & - & - & - & - & - \\
\hline 6. East Cottingwith & - & - & - & - & - \\
\hline 7. East Harnham & 5.7 & - & 0.11 & - & 8 \\
\hline 8. Moorlinch & 0.6 & 0.6 & 0.16 & 0.16 & 8 \\
\hline 9. Mottey Meadows & 1 & - & 0.13 & - & 8 \\
\hline 10. Nethercote & 0.41 & 0.73 & 0.1 & - & - \\
\hline 11. Portholme & 0.2 & 3.5 & 0.12 & 0.1 & 7 \\
\hline 12. Southlake & 0.08 & 1 & 0.12 & 0.14 & 7 \\
\hline 13. Stonygillfoot & 2.3 & 2.3 & 0.1 & 0.1 & 11 \\
\hline 14. Tadham & 2.5 & 1.75 & 0.15 & 0.15 & 8 \\
\hline 15. Tadham ESA & 2.5 & 1.75 & 0.15 & 0.15 & 8 \\
\hline 16. Upton Ham & 0.9 & 0.7 & 0.11 & 0.11 & 5 \\
\hline 17. Upwood & 0.22 & 0.01 & 0.06 & 0.02 & 3 \\
\hline 18. Westhay ESA & 2.5 & 1.75 & 0.15 & 0.15 & 8 \\
\hline 19. West Sedgemoor & 1.5 & 1.5 & 0.27 & 0.27 & 6.4 \\
\hline 20. Wet Moor & 0.1 & 3.35 & 0.06 & 0.15 & 8 \\
\hline
\end{tabular}

Continuation of the table 1

\begin{tabular}{|l|c|c|c|c|c|}
\hline \multicolumn{1}{|c|}{ Site Name } & $\begin{array}{c}\text { Rainfall } \\
(\mathbf{m m})\end{array}$ & $\begin{array}{c}\text { Potential } \\
\text { transpiration } \\
(\mathbf{m m})\end{array}$ & $\begin{array}{c}\text { SMD (mm) } \\
(\mathbf{e n d} \text { July })\end{array}$ & $\begin{array}{c}\text { Drought } \\
\text { threshold } \\
(\mathbf{c m})\end{array}$ & $\begin{array}{c}\text { Aeration } \\
\text { threshold } \\
(\mathbf{c m})\end{array}$ \\
\cline { 2 - 6 } & $x_{6}$ & $x_{7}$ & $x_{8}$ & $x_{9}$ & $x_{10}$ \\
\hline 1. Belaugh & 575 & 531 & 107 & 49.4 & 35.7 \\
\hline 2. Blackthorn & 669 & 511 & 90 & 48.5 & 23.5 \\
\hline 3. Broaddale & 1663 & 375 & 0 & 47.7 & 30.4 \\
\hline 4. Cricklade & 726 & 503 & 82 & 44.6 & 34.1 \\
\hline 5. Dancing Gate & 1045 & 444 & 39 & 46.4 & 35.9 \\
\hline 6. East Cottingwith & 643 & 486 & 85 & - & - \\
\hline 7. East Harnham & 799 & 511 & 86 & 49.6 & 44.3 \\
\hline 8. Moorlinch & 865 & 523 & 85 & 46.8 & 27.3 \\
\hline 9. Mottey Meadows & 700 & 498 & 86 & 46.4 & 25.6 \\
\hline 10. Nethercote & 726 & 503 & 82 & 49.1 & 28.9 \\
\hline 11. Portholme & 574 & 523 & 103 & 48.3 & 38.7 \\
\hline 12. Southlake & 865 & 523 & 85 & 48.7 & 42.0 \\
\hline 13. Stonygillfoot & 1068 & 404 & 33 & 47.4 & 23.3 \\
\hline 14. Tadham & 865 & 523 & 85 & 48.8 & 35.6 \\
\hline 15. Tadham ESA & 865 & 523 & 85 & 48.8 & 35.6 \\
\hline 16. Upton Ham & 775 & 514 & 78 & 48.2 & 35.6 \\
\hline 17. Upwood & 574 & 523 & 103 & 48.5 & 23.5 \\
\hline 18. Westhay ESA & 865 & 523 & 85 & 48.8 & 35.6 \\
\hline 19. West Sedgemoor & 865 & 523 & 85 & 49.3 & 44.7 \\
\hline 20. Wet Moor & 865 & 523 & 85 & 49.3 & 42.7 \\
\hline
\end{tabular}


3. General biotechnical regularity. Inductively, on the basis of tens of thousands of examples of identification of statistical selections from various areas of science, two generalized mathematical models [2-5] were revealed:

a) the generalized determined (trend) model for identification on values of factors and communications between them (it is shown in this article);

b) the general wave function of oscillatory indignation of the studied system in the form of an asymmetric wavelet signal (it is offered according to primary not grouped data).

All tendencies are modelled by binomial regularity of a look

$$
y=a_{1} x^{a_{2}} \exp \left(-a_{3} x^{a_{4}}\right)+a_{5} x^{a_{6}} \exp \left(-a_{7} x^{a_{8}}\right),
$$

where $y$-estimated parameter (parameter is an indicator of the studied system),

$x$ - the influencing parameter, in an example of [1] 10 measured factors on 20 values.

4. A rating of the influencing and dependent factors. The full correlation matrix (without rank distributions) binary (between couples of mutually influencing factors) communications between 10 factors is given in table 2 .

Table 2. Correlation matrix of the full factorial analysis and rating of factors

\begin{tabular}{|l|c|c|c|c|c|}
\hline \multirow{2}{*}{ The influencing factors (parameters $x$ ) } & \multicolumn{5}{c|}{ Dependent factors (indicators $y$ ) } \\
\cline { 2 - 7 } & $x_{1}$ & $x_{2}$ & $x_{3}$ & $x_{4}$ & $x_{5}$ \\
\hline Topsoil hydraulic conductivity (m day) $x_{1}$ & 1 & 0.5382 & 0.6028 & 0.6337 & 0.6409 \\
\hline Subsoil hydraulic conductivity (m day) $x_{2}$ & 0.8652 & 1 & 0.4973 & 0.6772 & 0.8634 \\
\hline Topsoil drainable porosity $x_{3}$ & 0.3666 & 0.2321 & 1 & 0.9079 & 0.4495 \\
\hline Subsoil drainable pororsity $x_{4}$ & 0.5910 & 0.5206 & 0.9293 & 1 & 0.7528 \\
\hline Unsaturated Hydraulic conductivity exponent $x_{5}$ & 0.6068 & 0.6989 & 0.4786 & 0.6994 & 1 \\
\hline Rainfall (mm) $x_{6}$ & 0.2550 & 0.2250 & 0.0739 & 0.2373 & 0.5864 \\
\hline Potential transpiration $(m m) x_{7}$ & 0.0176 & 0.1490 & 0.2092 & 0.3188 & 0.4963 \\
\hline SMD (mm) (end July) $x_{8}$ & 0.0167 & 0.2099 & 0.1194 & 0.2223 & 0.6612 \\
\hline Drought threshold (cm) $x_{9}$ & 0.5277 & 0.1634 & 0.1783 & 0.3824 & 0.0596 \\
\hline Aeration threshold (cm) $x_{10}$ & 0.3202 & 0.4632 & 0.3848 & 0.6131 & 0.2246 \\
\hline Sum of coefficients of correlation $\Sigma r$ & 4.5668 & 4.2003 & 4.4736 & 5.6921 & 5.7347 \\
\hline Indicator place $I_{y}$ & 8 & 10 & 9 & 5 & 4 \\
\hline
\end{tabular}

Continuation of the table 2

\begin{tabular}{|c|c|c|c|c|c|c|c|}
\hline \multirow{2}{*}{$\begin{array}{c}\text { Parameters } \\
x\end{array}$} & \multicolumn{4}{|c|}{ Dependent factors (indicators $y)$} & Sum & Place \\
\cline { 2 - 6 }$x_{6}$ & $x_{7}$ & $x_{8}$ & $x_{9}$ & $x_{10}$ & $\Sigma r$ & $I_{x}$ \\
\hline$x_{1}$ & 0.3702 & 0.3698 & 0.4575 & 0.5232 & 0.4469 & 5.5832 & 4 \\
\hline$x_{2}$ & 0.3517 & 0.3790 & 0.6024 & 0.6294 & 0.8915 & 6.7571 & $\mathbf{1}$ \\
\hline$x_{3}$ & 0.0033 & 0.3565 & 0.1194 & 0.4246 & 0.3474 & 4.2073 & 9 \\
\hline$x_{4}$ & 0.3726 & 0.6964 & 0.6342 & 0.4903 & 0.7067 & 6.6939 & $\mathbf{2}$ \\
\hline$x_{5}$ & 0.2785 & 0.6658 & 0.5374 & 0.1581 & 0.7606 & 5.8841 & $\mathbf{3}$ \\
\hline$x_{6}$ & 1 & 0.9021 & 0.9525 & 0.1825 & 0.4483 & 4.8630 & 7 \\
\hline
\end{tabular}




\begin{tabular}{|c|c|c|c|c|c|c|c|}
\hline \multirow{2}{*}{$\begin{array}{c}\text { Parameters } \\
x\end{array}$} & \multicolumn{5}{|c|}{ Dependent factors (indicators $y$ ) } & \multirow{2}{*}{$\begin{array}{l}\text { Sum } \\
\sum r\end{array}$} & \multirow{2}{*}{$\begin{array}{c}\text { Place } \\
I_{x}\end{array}$} \\
\hline & $x_{6}$ & $x_{7}$ & $x_{8}$ & $x_{9}$ & $x_{10}$ & & \\
\hline$x_{7}$ & 0.8767 & 1 & 0.9514 & 0.5864 & 0.3902 & 4.9956 & 6 \\
\hline$x_{8}$ & 0.9363 & 0.9683 & 1 & 0.4164 & 0.9553 & 5.5058 & 5 \\
\hline$x_{9}$ & 0.2545 & 0.5205 & 0.4263 & 1 & 0.6013 & 4.1140 & 10 \\
\hline$x_{10}$ & 0.3716 & 0.3828 & 0.3417 & 0.5029 & 1 & 4.6049 & 8 \\
\hline$\sum r$ & 4.8154 & 6.2412 & 6.0228 & 4.9138 & 6.5482 & 53.2089 & - \\
\hline Place $I_{y}$ & 7 & 2 & 3 & 6 & 1 & - & 0.5321 \\
\hline
\end{tabular}

Follows from the concept of a correlative variation of $\mathrm{Ch}$. Darwin that in other conditions of dwelling other combinations of values of factors of the soil can be stronger (Darwin calls factors hereditary evasion). Therefore weak factorial communications can be stronger on other objects of research. You need to compare pastures from different regions of the Earth. In the end there is a mathematical tool to compare the environmental systems of pastures between them.

The coefficient of functional connectivity (in the wider biotechnological meaning correlative variation) 10 factors equal $53.2089 / 10^{2}=0.5321$. This criterion is applied by comparison of different phytocenoses, in particular, of pastures from different regions.

According to table 2 among the influencing factors first place was won by a factor $x_{2}$ (Subsoil hydraulic conductivity), the second $-x_{4}$ (Subsoil drainable pororsity) and the third $-x_{5}$ (Unsaturated Hydraulic conductivity exponent). Among dependent factors (indicators) in ranked first factor (Aeration threshold), and the second - (Potential transpiration) and the third - (SMD end July).

5. Correlation matrix of the binary relations. We will exclude a rating and cages with units on a diagonal (tab. 3) from data of table 2.

Table 3. Correlation matrix of the binary relations between factors

\begin{tabular}{|c|c|c|c|c|c|c|c|c|c|c|}
\hline & $x_{1}$ & $x_{2}$ & $x_{3}$ & $x_{4}$ & $x_{5}$ & $x_{6}$ & $x_{7}$ & $x_{8}$ & $x_{9}$ & $x_{10}$ \\
\hline$x_{1}$ & & 0.5382 & 0.6028 & 0.6337 & 0.6409 & 0.3702 & 0.3698 & 0.4575 & 0.5232 & 0.4469 \\
\hline$x_{2}$ & 0.8652 & & 0.4973 & 0.6772 & 0.8634 & 0.3517 & 0.3790 & 0.6024 & 0.6294 & 0.8915 \\
\hline$x_{3}$ & 0.3666 & 0.2321 & & 0.9079 & 0.4495 & $\mathbf{0 . 0 0 3 3}$ & 0.3565 & 0.1194 & 0.4246 & 0.3474 \\
\hline$x_{4}$ & 0.5910 & 0.5206 & 0.9293 & & 0.7528 & 0.3726 & 0.6964 & 0.6342 & 0.4903 & 0.7067 \\
\hline$x_{5}$ & 0.6068 & 0.6989 & 0.4786 & 0.6994 & & 0.2785 & 0.6658 & 0.5374 & 0.1581 & 0.7606 \\
\hline$x_{6}$ & 0.2550 & 0.2250 & 0.0739 & 0.2373 & 0.5864 & & 0.9021 & 0.9525 & 0.1825 & 0.4483 \\
\hline$x_{7}$ & 0.0176 & 0.1490 & 0.2092 & 0.3188 & 0.4963 & 0.8767 & & 0.9514 & 0.5864 & 0.3902 \\
\hline$x_{8}$ & 0.0167 & 0.2099 & 0.1194 & 0.2223 & 0.6612 & 0.9363 & $\mathbf{0 . 9 6 8 3}$ & & 0.4164 & 0.9553 \\
\hline$x_{9}$ & 0.5277 & 0.1634 & 0.1783 & 0.3824 & 0.0596 & 0.2545 & 0.5205 & 0.4263 & & 0.6013 \\
\hline$x_{10}$ & 0.3202 & 0.4632 & 0.3848 & 0.6131 & 0.2246 & 0.3716 & 0.3828 & 0.3417 & 0.5029 & \\
\hline
\end{tabular}

Then we will receive a set of coefficients of correlation at binary communications. The 
maximum adequacy 0.9683 is observed at dependence $x_{7}=f\left(x_{8}\right)$. The minimum coefficient of correlation 0.0033 is equal for the relation $x_{6}=f\left(x_{3}\right)$.

Above the known level of adequacy 0.7 there are 15 binary communications (tab. 4) that makes $100 \times 15 /\left(10^{2}-10\right)=16.67 \%$. Thus the share of the strongest binary relations is very far from a gold proportion of $61.80 \%$.

Table 4. Correlation matrix of the binary relations at correlation $r \geq 0,7$

\begin{tabular}{|c|c|c|c|c|c|c|c|c|}
\hline & $x_{1}$ & $x_{3}$ & $x_{4}$ & $x_{5}$ & $x_{6}$ & $x_{7}$ & $x_{8}$ & $x_{10}$ \\
\hline$x_{2}$ & 0.8652 & & & 0.8634 & & & & 0.8915 \\
\hline$x_{3}$ & & & 0.9079 & & & & & \\
\hline$x_{4}$ & & 0.9293 & & 0.7528 & & & & 0.7067 \\
\hline$x_{5}$ & & & & & & & & 0.7606 \\
\hline$x_{6}$ & & & & & & 0.9021 & 0.9525 & \\
\hline$x_{7}$ & & & & & 0.8767 & & 0.9514 & \\
\hline$x_{8}$ & & & & & 0.9363 & 0.9683 & & 0.9553 \\
\hline
\end{tabular}

The grayed out the block from pair communications between three factors is allocated $x_{6}$, $x_{7}$ and $x_{8}$.

In table 5 compact records of values of parameters of model are given (1).

Table 5. Parameters of regularities of mutual influence of indicators

\begin{tabular}{|c|c|c|c|c|c|c|c|c|c|c|}
\hline \multirow{2}{*}{ Factors } & \multicolumn{7}{|c|}{$y=a_{1} x^{a_{2}} \exp \left(-a_{3} x^{a_{4}}\right)+a_{5} x^{a_{6}} \exp \left(-a_{7} x^{a_{8}}\right)$} & \multirow{2}{*}{\begin{tabular}{c} 
Correl. \\
coef. \\
\cline { 3 - 12 }
\end{tabular}} \\
\cline { 2 - 12 } & $y$ & $a_{1}$ & $a_{2}$ & $a_{3}$ & $a_{4}$ & $a_{5}$ & $a_{6}$ & $a_{7}$ & $a_{8}$ & $r$ \\
\hline$x_{8}$ & $x_{7}$ & 374.70374 & 0 & 0.026208 & 1 & $6.51818 \mathrm{e} 6$ & 5.08560 & 16.64811 & 0.14794 & 0.9683 \\
\hline$x_{8}$ & $x_{10}$ & $3.22802 \mathrm{e} 7$ & 8.18164 & 23.41995 & 0.17105 & 0 & 0 & 0 & 0 & 0.9553 \\
\hline$x_{6}$ & $x_{8}$ & 40.23982 & 0 & -0.0023136 & 1 & $-4.55658 \mathrm{e}-8$ & 3.29629 & 0 & 0 & 0.9525 \\
\hline$x_{7}$ & $x_{8}$ & $-1.14232 \mathrm{e} 7$ & 0 & 1.53724 & 0.34910 & 0.0044124 & 1.60871 & 0 & 0 & 0.9514 \\
\hline$x_{8}$ & $x_{6}$ & 1652.6879 & 0 & 0.028053 & 0.74615 & 0 & 0 & 0 & 0 & 0.9363 \\
\hline$x_{4}$ & $x_{3}$ & 0.057820 & 0 & -5.07272 & 0.92808 & 0 & 0 & 0 & 0 & 0.9293 \\
\hline$x_{3}$ & $x_{4}$ & 0.033043 & 0 & 0 & 0 & 1.26462 & 1.28611 & 0 & 0 & 0.9079 \\
\hline$x_{6}$ & $x_{7}$ & 227.60211 & 0 & -0.0020124 & 1 & $-5.09798 \mathrm{e}-7$ & 3.12871 & 0 & 0 & 0.9021 \\
\hline$x_{2}$ & $x_{10}$ & 23.75135 & 0 & -0.017314 & 2.67978 & 17.15156 & 1.95212 & 0.051754 & 6.18305 & 0.8915 \\
\hline$x_{7}$ & $x_{6}$ & 386020.2 & 0 & 0.0078186 & 0.94425 & -6774.0186 & 0.83325 & 0.014992 & 0.89617 & 0.8767 \\
\hline$x_{2}$ & $x_{1}$ & 0.49583 & 0 & 0.45055 & 1 & 39.61873 & 12.39564 & 5.60147 & 1.00944 & 0.8652 \\
\hline$x_{2}$ & $x_{5}$ & 3.02871 & 0 & 0.37467 & 1 & 7.85863 & 1.18715 & 0.47018 & 1 & 0.8634 \\
\hline$x_{5}$ & $x_{10}$ & 4.28454 & 2.38270 & 0.27272 & 1.12590 & 0 & 0 & 0 & 0 & 0.7606 \\
\hline$x_{4}$ & $x_{5}$ & 2.79236 & 0 & -3.31653 & 18.59787 & $1.75307 \mathrm{e} 8$ & 4.77904 & 23.86727 & 0.55696 & 0.7528 \\
\hline$x_{4}$ & $x_{10}$ & 23.48359 & 0 & 8.22510 & 1 & 996.42298 & 1.43515 & 5.22215 & 1 & 0.7067 \\
\hline
\end{tabular}

In total three clusters of regularities were formed. 
6. First cluster. It possesses good symmetry (tab. 6).

Table 6. First cluster of the strongest communications

\begin{tabular}{|c|c|c|c|}
\hline & $x_{6}$ & $x_{7}$ & $x_{8}$ \\
\hline$x_{6}$ & & 0.9021 & 0.9525 \\
\hline$x_{7}$ & 0.8767 & & 0.9514 \\
\hline$x_{8}$ & 0.9363 & 0.9683 & \\
\hline
\end{tabular}
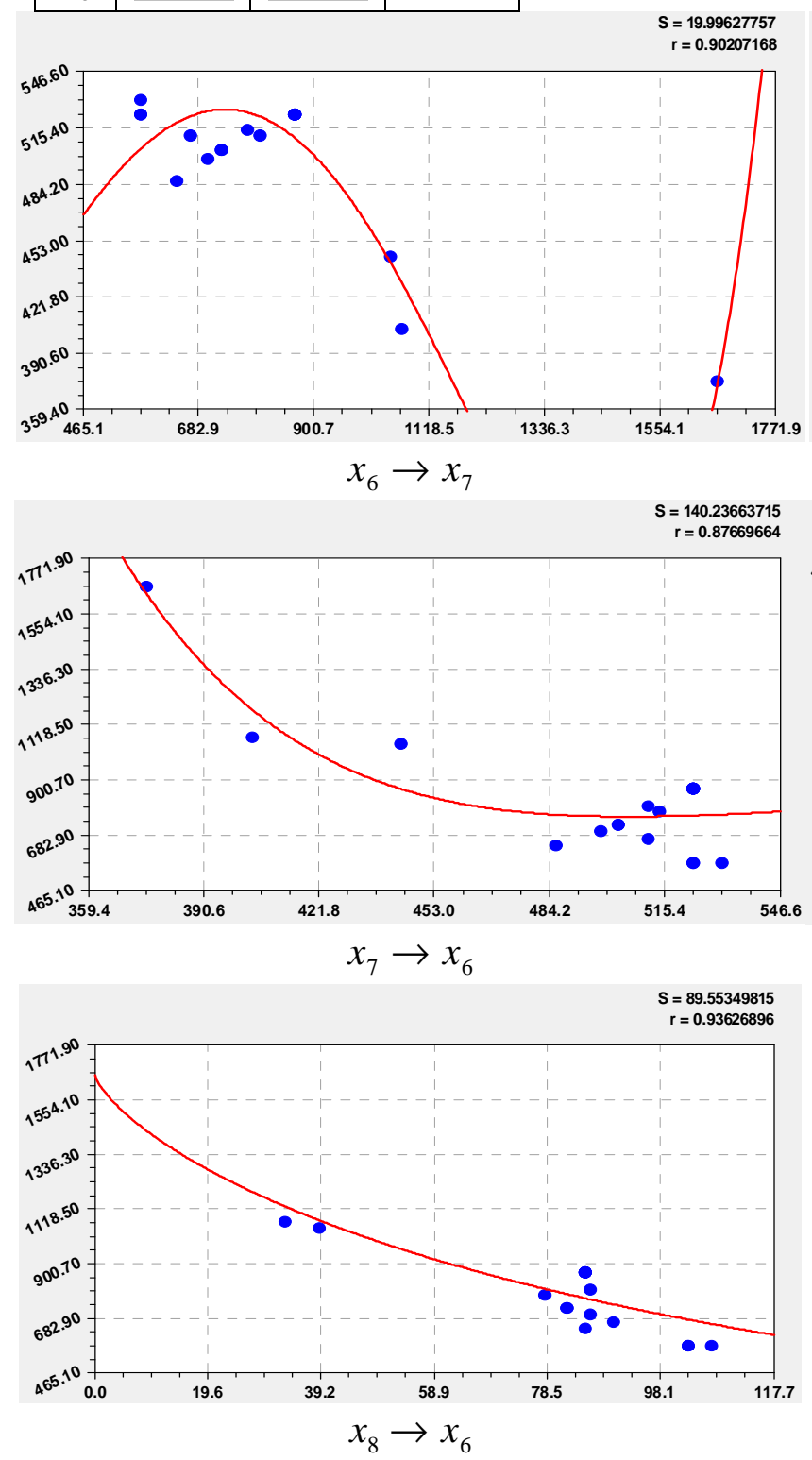

Figure 1. Schedules of the binary relations of the first cluster of regularities

Because of repetitions of values only 12 points were formed of 20 names of the sites. Apparently from figure 1 , these 12 points form a big cluster of basic data of nine points located closely to each other. Thus, the clustering occurs not only on regularities, but also on values of the factors entering these biotechnical regularities. As a result when using all primary data there will be also wave indignations. 
7. Second cluster. It was defined (tab. 7) influence on an indicator $x_{10}$ (Aeration threshold) four influencing variable $x_{2}$ (Subsoil hydraulic Table 7. Second cluster of strong conductivity), $x_{4}$ (Subsoil drainable pororsity), $x_{5}$ (Unsaturated Hydraulic conductivity exponent) and $x_{8}$ (SMD end July).

In figure 2 schedules of the binary relations are shown. The coefficient of correlation $r$ is given in the right top corner of the schedule.
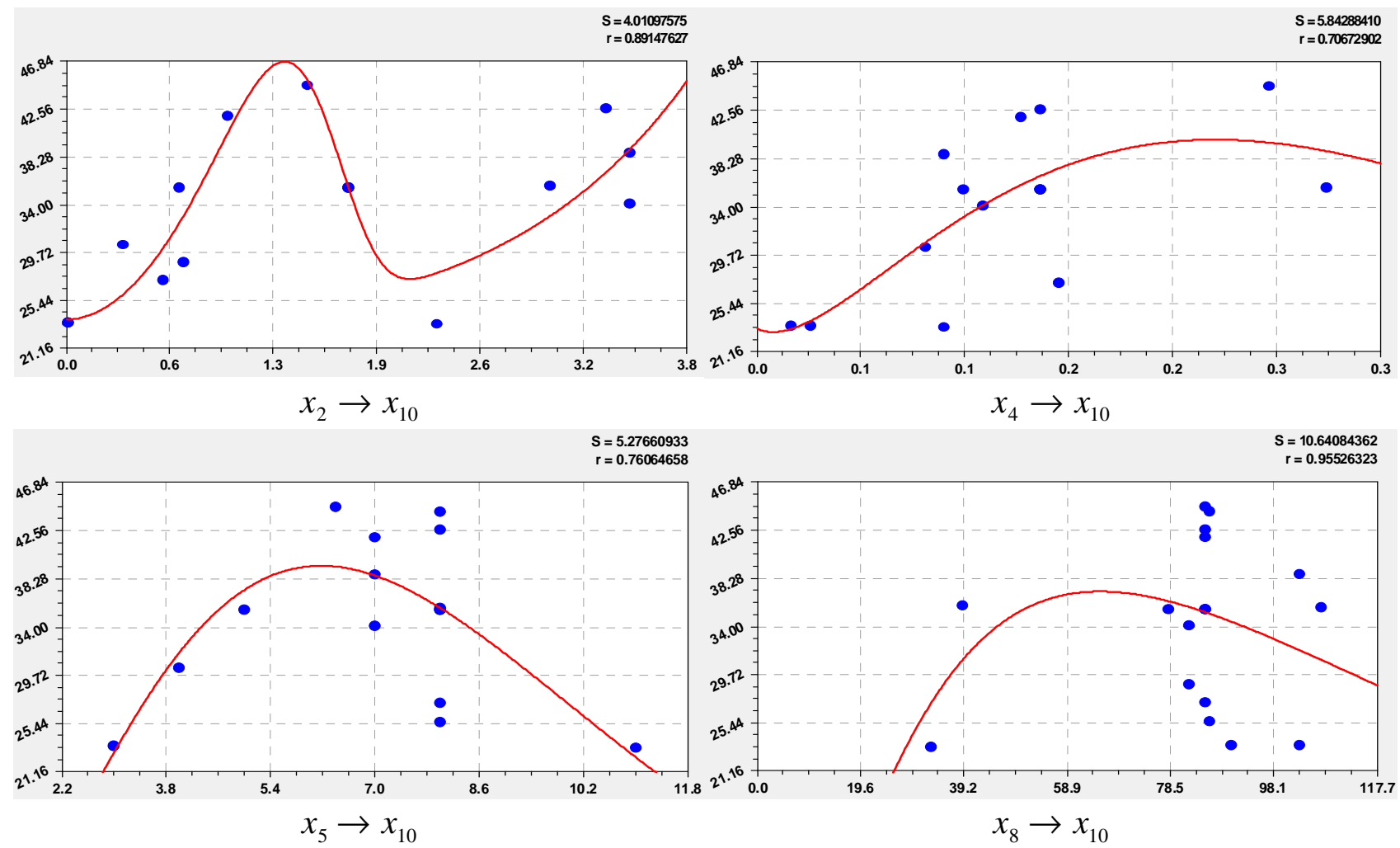

Figure 2. Schedules of the binary relations of the second cluster of regularities

8. Third cluster. It (tab. 8) is received by addition to the group of regularities of influence of $x_{5}$ which is available in the table 4 (Unsaturated Hydraulic conductivity exponent).

Table 8. Third cluster of the binary relations

\begin{tabular}{|c|c|c|c|c|c|}
\hline & $x_{1}$ & $x_{2}$ & $x_{3}$ & $x_{4}$ & $x_{5}$ \\
\hline$x_{2}$ & 0.8652 & & & & 0.8634 \\
\hline$x_{3}$ & & & & 0.9079 & \\
\hline$x_{4}$ & & & 0.9293 & & 0.7528 \\
\hline$x_{5}$ & 0.6068 & 0.6989 & & 0.6994 & \\
\hline
\end{tabular}

This influence on three indicators $x_{1}$ (Topsoil hydraulic conductivity), $x_{2}$ (Subsoil hydraulic conductivity) and $x_{4}$ (Subsoil drainable pororsity) happens to correlation coefficients less than 0,7 .

In figure 3 schedules of eight binary relations are given. In addition to the table 5 influence happens on formulas:

$$
\begin{gathered}
x_{4}=0.00089702 x_{5}^{5.30108} \exp \left(-0.72580 x_{5}^{0.99904}\right) ; \\
x_{2}=9.97568 \cdot 10^{7} x_{5}^{18.18652} \exp \left(-28.52592 x_{5}^{0.31926}\right) ; \\
x_{1}=3.11204 \cdot 10^{-6} x_{5}^{20.53199} \exp \left(-4.05046 x_{5}\right)+1.55852 \cdot 10^{-48} x_{5}^{89.91067} \exp \left(-9.51579 x_{5}\right) .
\end{gathered}
$$



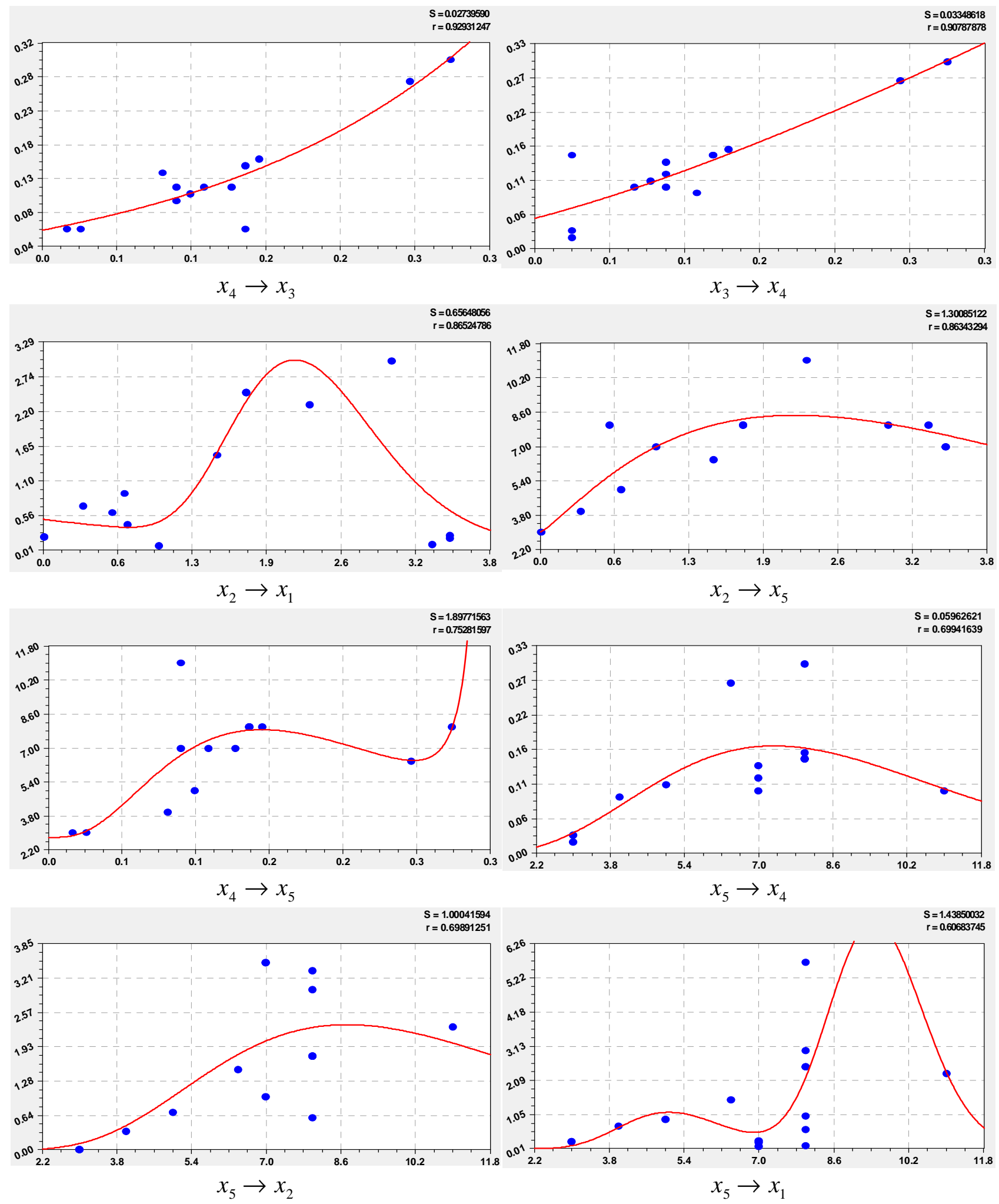

Figure 3. Schedules of the binary relations of the third cluster of regularities

When the same design of the general model (1) specific design patterns varies greatly, so get differing in complexity graphics.

Conclusions. Between biochemical substances of the soil of pastures and hydrological parameters of the water mode always there is a homeostasis. On the general tabular model [1], after identification of strong factorial communications, it is quite possible to define optimum or rational values at all 10 factors. And then on statistical models to predict the productivity of hayfields and 
pastures on the rational values of the factors. You can then proceed to parametric substantiation of measures for improvement of the water regime of riparian areas.

\section{References}

1. The Water Regime Requirements and the Response to Hydrological Change of Grassland Plant Communities. DEFRA-commissioned project BD1310. Final report to the Department for Environment, Food and Rural Affairs. Project leader: Dr D.J.G. Gowing (Open University). Project co-ordinator: Dr C.S. Lawson (Reading University). Co-authors: Prof E.G. Youngs (Cranfield University); K.R. Barber (Environment Agency); Prof J.S. Rodwell (Lancaster University); Dr M.V. Prosser (Ecological Surveys, Bangor); Dr H.L. Wallace (Ecological Surveys, Bangor); J.O. Mountford (CEH, Monks Wood); Prof G. Spoor (Gordon Spoor Associates). Institute of Water and Environment. Silsoe. Bedford. November 2002. 98 p.

2. Mazurkin P.M. Method of identification $/ / 14^{\text {th }}$ International multidisciplinary scientific geoconferenct \& SGEM2014. GeoConference jn NANO, BIO AND GREEN - TECHNOLOGIES

FOR A SUSTAINABLE FUTURE. Conference proceedincs. Volume 1. Section Advances in Biotechnology. 17-26 June 2014. Albena, Bulgaria. P. 427-434.

3. Mazurkin P.M. Factor analysis of the technical level of sibgle-bucket hydraulic excavators // International Journal of Engineering and Innovative Technology (IJEIT), Volume 3, Issue 9, March 2014. p.84-92.

4. Mazurkin P.M. Statistical modeling of entire prime numbers / International Journal of Engineering and Technical Research (IJETR) ISSN: 2321-0869, Volume-2, Issue-8, August 2014. P.148-158.

5. Mazurkin P.M., Tishin D.V. Wave dynamics of tree-ring width jf Oak // Integrated Journal of British. Volume 2. 2015. Issue 1. JAN-FEB. P. 55-67. IJBRITISH-223-PA.pdf. 